\title{
O ENVELHECIMENTO NO TRABALHO NA PERSPECTIVA DE TRABALHADORES DA ÁREA DE ENFERMAGEM
}

\author{
AGING AT WORK FROM THE PERSPECTIVE OF WORKERS IN THE AREA OF NURSING
}

EL ENVEJECIMIENTO EN EL TRABAJO DESDE LA PERSPECTIVA DE LOS TRABAJADORES

DE ENFERMERIA

Marcia Renata Rodrigues ${ }^{1}$

Ana Cristina Passarella Brêtas ${ }^{2}$

Resumo Este estudo qualitativo objetivou compreender os significados que os trabalhadores da enfermagem atribuem ao próprio processo de envelhecimento no mercado de trabalho, identificando implicações na saúde individual e familiar. Foi utilizado o método da história oral temática, com vinte trabalhadores da enfermagem de hospital público na cidade de Marília, São Paulo. Na análise, emergiram três categorias: história do trabalho na vida, história sobre saúde e adoecimento no e/ou pelo trabalho e história do envelhecimento no e/ou pelo trabalho. Depreendemos que o trabalho ocupa lugar de destaque; além de garantir a subsistência, propicia a participação na sociedade. Encontramos relatos de insatisfação com o trabalho, relacionada principalmente à maneira como ele está organizado. Concluímos que o trabalho continua sendo uma atividade importante durante toda a vida, e o ambiente e a forma como o trabalho está organizado influenciam no processo de envelhecimento. O grande desafio para a enfermagem é formular proposições que impliquem real melhoria da condição dos seus trabalhadores.

Palavras-chave envelhecimento; trabalho; saúde; enfermagem; recursos humanos de enfermagem no hospital.
Abstract This study aimed to understand the meanings that the nursing workers attribute to the aging process in the labor market, identifying implications for individual and family health. The thematic oral history method was used with twenty nurses at a public hospital in the city of Marília, state of São Paulo, Brazil. The analysis revealed three categories: work history in life; stories about health and illness in and/or through work; history of aging and/or for work. We inferred that work is a major concern; in addition to allowing one to earn a living, it promotes participation in society. We found reports of dissatisfaction with work related mainly to the way it is organized. We conclude that work remains an important activity throughout life, and the environment and the way work is organized influence the aging process. The major challenge for nursing is to formulate propositions that afford real improvements to the workers' conditions.

Keywords ethics; labor market; specialization; oral health. 


\section{Introdução}

O trabalho tem papel fundamental na vida e, portanto, na saúde dos indivíduos. Ele em si não é nocivo e perigoso, como se intrinsecamente possuísse esses atributos, mas o que o torna nocivo e perigoso é exatamente a forma pela qual ele é organizado pelo próprio homem (Dejours, 1986).

Os trabalhadores de cuidado à saúde, particularmente a equipe de enfermagem, são confrontados diariamente com exposições, tais como doenças infecciosas, agentes químicos, violência, turnos e perigos ergonômicos. Somados aos estressores psicológicos relacionados à carga de trabalho e ao ambiente de trabalho, cumulativamente aumentam os riscos do trabalho (Sofie, Belza e Young, 2003; Yassi, Gilbert e Cvitkovich, 2005). Logo, o ambiente hospitalar apresenta uma série de riscos à saúde do trabalhador, os quais podem provocar alterações do bem-estar emocional e físico, apontando assim para a complexidade no processo de trabalho e adaptação do trabalhador de enfermagem (Gonçalves e Magalhães, 2003).

Dessa maneira, no hospital, o processo de trabalho da enfermagem tem particularidades, decorrentes da maneira como ele é organizado e desenvolvido, sobrepondo aos trabalhadores cargas de trabalho específicas - que trazem repercussões importantes à sua saúde física e mental (Secco et al., 2010) e levam o trabalhador a procurar o serviço de saúde em busca de solução para o seu problema, com o frequente afastamento do trabalho.

A esse respeito, indagamos: após esse afastamento, os trabalhadores voltam melhores ou piores, para quem ou para o quê? Diante dessa sobrecarga, como estão envelhecendo? Quais as implicações dos problemas de saúde decorrentes do trabalho para o envelhecimento?

Guimarães e colaboradores (2003) analisaram a produção científica referente à organização e às relações de trabalho em enfermagem durante o período de 1971 a 2002. Ao considerar a totalidade do conhecimento produzido, observaram que os autores se preocuparam em analisar as relações interpessoais. Também foram investigadas as relações entre trabalho, enfermagem e biossegurança; trabalho e processo saúde-doença; enfermagem e saúde mental; hospital e saúde pública. No caso da organização do trabalho, foram estudados: rotatividade de pessoal, condições de trabalho, avaliação de serviços, tecnologias e assistência, divisão social do trabalho, sistema de comunicações.

Enfim, a produção do conhecimento tem se pautado na preocupação com a saúde do trabalhador no que se refere aos riscos biológicos, químicos, físicos, ergonômicos e psicológicos aos quais estão expostos, mas pouco, ou quase nada, aborda as repercussões de tais riscos sobre o envelhecimento desses trabalhadores. Fala-se da compreensão dos modos de viver, adoecer 
e morrer na atualidade, mas o modo de envelhecer não é citado, e não parece estar contido no modo de viver.

Nesse contexto, ressaltamos que o envelhecimento é um fenômeno natural e processual, que vai do útero ao túmulo, contém a fase da velhice, mas não se esgota nela, ou seja, entendemos o envelhecimento como um processo de vida. A qualidade de vida e, consequentemente, a qualidade do envelhecimento se relacionam com a visão de mundo do indivíduo e da sociedade em que ele está inserido, bem como com o 'estilo de vida' conferido a cada ser (Brêtas e Oliveira, 2000).

Durante a realização da pesquisa de mestrado As relações entre as concepções dos idosos e dos auxiliares de enfermagem sobre o cuidado em ambiente hospitalar, para melhor entendimento das relações de cuidado estabelecidas com os idosos, levamos em conta não só as condições de trabalho, mas também as questões individuais dos que prestavam cuidados. Dessa forma, investigamos como essas pessoas encaravam o seu próprio envelhecimento. Nesta pesquisa, constatamos que a relação envelhecimento-perda foi mais frequente na fala dos profissionais, havendo também dificuldade em falar e reconhecer o próprio envelhecimento (Rodrigues, 2002).

No que diz respeito às mentalidades dos aposentados sobre o processo de envelhecimento no mercado de trabalho, Brêtas e Oliveira (2000) perceberam nas narrativas que os depoentes atribuíram significados diversos a esse processo quando se referiam ao envelhecimento do outro. Entretanto, quando o foco da discussão era o próprio entrevistado, ele foi descrito como um fenômeno imperceptível enquanto estava sendo vivenciado.

O envelhecimento, tal qual a saúde, é silencioso; nós não os percebemos na sua plenitude. Na maior parte das vezes, apenas os identificamos quando adoecemos. Dados históricos demonstram que a realidade social em qualquer país capitalista é marcada pela desigualdade social, fruto da má distribuição de renda. Essa desigualdade é observada no âmago do trabalho, uma vez que o local que o indivíduo ocupa na sociedade reflete o lugar que ocupa no sistema produtivo e vice-versa. Quanto maior a desigualdade social, maior será a repercussão na qualidade de vida da sociedade de uma forma geral e do indivíduo e sua família em particular (Brêtas e Oliveira, 2000).

Reconhecendo - e concordando com Brêtas e Oliveira (2000) - que falar sobre saúde e envelhecimento visando à qualidade de vida, num momento em que a precarização do trabalho e a exclusão social são realidade mundial, é um grande desafio para os profissionais da gerontologia, da enfermagem e da saúde coletiva, este estudo tem como objetivo compreender os significados que os trabalhadores da área de enfermagem atribuem ao próprio processo de envelhecimento, identificando as implicações no seu trabalho e na sua saúde. 
Metodologia: entrevistas com base nos eixos trabalho e envelhecimento

Participaram do estudo vinte trabalhadores da enfermagem: dez auxiliares de enfermagem (sete mulheres e três homens), cinco atendentes de enfermagem (três mulheres e dois homens) e cinco enfermeiros (três mulheres e dois homens). A idade das mulheres (atendentes e auxiliares de enfermagem) variou de 51 a 61 anos; dos homens (auxiliares e atendentes de enfermagem), de 41 a 83 anos; e dos enfermeiros e enfermeiras, de 44 a 53 anos.

As três perguntas do questionário relacionam-se às mudanças no mercado de trabalho na odontologia, Os critérios de inclusão para participar do estudo foram: ter quarenta anos ou mais de idade; no mínimo dez anos de experiência profissional na área de enfermagem na própria instituição; e concordar em tomar parte da pesquisa após conhecimento prévio dos seus objetivos e etapas.

Os dados foram coletados por meio de entrevistas com roteiro semiestruturado, realizadas individualmente, gravadas e transcritas pela primeira autora. Duraram em média trinta minutos. Para atingir os objetivos propostos, as entrevistas foram realizadas com base nos eixos trabalho e envelhecimento. A partir deles, o roteiro foi composto pelas seguintes questões norteadoras: como é a sua rotina de trabalho? Como são as relações no trabalho? Que lugar o trabalho ocupa na sua vida e que significado você atribui a ele? Você já teve algum problema de saúde ou afastamento durante esses anos de profissão? Se sim, fale sobre isso. Você já se percebeu envelhecendo? O que significa ser velho para você? O que significa envelhecer no mercado de trabalho? Você faria tudo de novo?

As narrativas foram analisadas utilizando-se o referencial da própria história oral (Thompson, 1998), que consiste em trazer a história, como ciência do acontecido e do acontecimento, para o diálogo com a história contada pelo próprio sujeito. Para análise e discussão das narrativas, após todas as transcrições finalizadas e releituras criteriosas, construíram-se três categorias: história do trabalho na vida; história sobre saúde e adoecimento no e/ou pelo trabalho; história do envelhecimento no e/ou pelo trabalho.

Trata-se de uma pesquisa qualitativa, ${ }^{3}$ na qual foi utilizado o método da história oral temática. Realizou-se em um hospital público na cidade de Marília, interior do estado de São Paulo. Todos os participantes assinaram o termo de consentimento livre e esclarecido, atendendo aos princípios éticos inerentes à pesquisa dessa natureza e à resolução n. 196/96 do Conselho Nacional de Saúde (Brasil, 1996). O projeto foi aprovado pelos Comitês de Ética em Pesquisa da Universidade Federal de São Paulo (CEP 836/09) e da Faculdade de Medicina de Marília (CEP 278/09). 


\section{Resultados e discussão: história do trabalho na vida}

Os recortes das narrativas serão apresentados sem detalhar idade, sexo e categoria profissional dos entrevistados, visando garantir o sigilo com eles acordado. Desta forma, será utilizada a letra E (entrevista) seguida de número ( 1 a 20), indicando a ordem que as entrevistas foram realizadas.

Quanto menos a pessoa se afasta do trabalho, mais ela se sente integrada à sociedade, o que possibilita analisar o convívio no trabalho como forma de interação social e amizades.

De maneira geral, os narradores veem como boas as relações sociais/afetivas no trabalho, falando da boa convivência com os colegas de trabalho e com os pacientes.

Muito boa. Eu tenho meus colegas de serviço como verdadeiros irmãos pra mim. Nem os dedos das nossas mãos são iguais, né? Então eu respeito a todos para as pessoas me respeitarem também. Assim a gente vai bem (E13).

$\mathrm{Eu}$ tenho relacionamento bom, não tenho relacionamento ruim com nenhum deles. Com os pacientes também. Aprendi a lidar com as pacientes mais difíceis, sei contornar a situação, porque a gente vai amadurecendo (E19).

Quanto às relações hierárquico-profissionais, pudemos apreender das falas dos narradores que eles sentem a necessidade de recuperar o direito de participar ativamente das decisões, de saber, de se fazerem presentes no cenário da instituição. No entanto, apesar da fala, não fica evidente se existe algum movimento por parte dos trabalhadores para garantir esse direito; parece que eles aguardam que, um dia talvez, esse espaço seja aberto pelos gestores, ou seja: deparamos com a ausência de esforços conjuntos para mudar a realidade. Parece existir um processo de alienação da realidade vivenciada.

O que se percebe, né, é que continua, no máximo, uma participação da gente no geral em termos de opinião, de ouvir um pouco o funcionário com relação à rotina. As coisas continuam sendo, digamos que impostas, né, você tendo que acatar. Às vezes gera (sic) algumas divergências de opinião só, mas de uma maneira geral, bem (E1).

Tem coisa que você vê lá longe que você sabe que podia mudar, que podia melhorar, tanto para o funcionário quanto pro andamento do serviço. A gente não pode opinar, né, porque eu sou 'peixe pequeno'. Não tem esse espaço, porque 
a gente já tentou fazer várias reuniões com a chefia, com a diretoria. Na hora eles ouvem a gente (...) e no dia seguinte volta tudo a mesma coisa. Ouve, mas não escuta, entendeu? (E11).

O que se nota é que a instituição é regida por uma administração vertical e hierarquizada, existindo uma distância entre o trabalhador e a administração e uma ausência de valorização do trabalhador como sujeito que age e interage para o processo de trabalho. Quanto menor a autonomia do trabalhador na organização da sua atividade, maiores as possibilidades de que a atividade gere transtornos à saúde mental (Glina et al., 2001).

A organização do trabalho determina não somente a divisão do trabalho, mas também a divisão das pessoas, tendo grande influência na saúde dos trabalhadores, principalmente no que se refere à carga psíquica do trabalho (Dejours, 2007). “Via de regra, quanto mais a organização do trabalho é rígida, mais a divisão do trabalho é acentuada, menor é o conteúdo significativo do trabalho e menores são as possibilidades de mudá-lo. Correlativamente, o sofrimento aumenta" (Dejours, 1992, p. 52). No cotidiano das instituições hospitalares, é comum presenciarmos situações envolvendo abusos de poder.

Eu posso dizer até questão de perseguição e retaliação em relação ao trabalho. À medida que você vai levando bordoada daqui, dali, você vai perdendo isso (...) mesmo que às vezes tenho uma visão das coisas tudo, mas se eu percebo que pode gerar um conflito, eu me resguardo, seguro pra mim, não me exponho mais... (E1).

Ela chegou a falar pra mim que eu não servia pra trabalhar aqui, ela falou que eu não era nem metade de um funcionário: "Não, você não é nem um quarto de funcionário, você não serve" (E3).

Essas relações hierárquicas, as quais envolvem abuso de poder, nos levam a um tema que, embora seja antigo, propicia novas discussões: o assédio moral. Ele está embasado no próprio sistema macroeconômico, que, em seu processo disciplinar, favorece o aparecimento dessa forma de violência, em que o superior hierárquico detém certo poder sobre seu subordinado (Heloani, 2004, 2005).

Existe uma intencionalidade, uma constante e deliberada desqualificação da vítima, seguida de sua consequente fragilização, com o intuito de neutralizá-la em termos de poder. Trata-se de um processo disciplinador em que se procura anular a vontade daquele que, para o agressor, se apresenta como ameaça (Heloani, 2004, 2005).

Com a reestruturação produtiva foi necessário reestruturar as pessoas, ou melhor, reestruturar a subjetividade delas, cooptá-las, envolvê-las, 
docilizá-las, e tudo isso em muito pouco tempo. O que tem acontecido, na prática, é a exigência de um trabalhador multifuncional, polivalente, que executa e toma decisões e também arca com as consequências de seus erros. As doenças nesse tipo de organização da produção, ao contrário do que se prognosticava, aumentaram e muito, principalmente as de ordem mental (Heloani, 2008).

Um fato que chama a atenção é que conforme os trabalhadores vão envelhecendo ou adoecendo acabam sendo transferidos para setores de menor complexidade ou exercendo atividades mais leves. Dessa forma, percebem como mais tranquila a atual rotina de trabalho. No entanto, ao mesmo tempo que poupa o trabalhador do desgaste físico, na maioria das vezes já estabelecido, a mudança de local de trabalho ou função pode causar a sensação de desvalorização do trabalho.

Depois que eu tive alguns probleminhas de saúde, minha chefe me arrumou esse cargo de apoio (...) Você está sempre atenta a servir a todos. No começo eu chorei muito, achei que não tava sendo útil (E13).

Essa também é uma realidade dos atendentes de enfermagem, por não poderem mais prestar cuidados diretos aos pacientes.

Ah, filha, foi terrível, terrível, foi a pior fase da minha vida. Foi quando a chefe falou assim: "Você não vai mais participar da enfermagem, vai sair." Nossa Senhora, eu queria morrer, foi terrível, por isso que eu falo: se fosse hoje, eu voltava tudo atrás e pegava com garra pra estudar e fazer meu curso de auxiliar (E10).

Eu trabalhei 14 anos dentro da hemodiálise. Lá também eu trabalhava igual todo mundo, aí eu saí de lá e sofri muito, fiquei doente porque eu gostava muito de lá (E15).

Embora a lei do exercício profissional n. 7.498/1986 e o decreto-lei n. 94.406/97 não contemplem os antigos atendentes de enfermagem, para os quais foi reservado um prazo de dez anos para qualificação formal como auxiliar de enfermagem, estes ainda se encontram atuando nos serviços de saúde de todo o país. Assim, nas instituições de saúde convivem trabalhadores contratados para exercer cargos/funções de denominações diversas (auxiliares de saúde, auxiliares de serviços médicos, auxiliares operacionais de serviços diversos etc.). Dentre estes, um número expressivo não completou o ensino fundamental, indispensável para a obtenção da certificação profissional como auxiliar de enfermagem (Brasil, 2001). Na instituição estudada por esta pesquisa, são denominados cargos de apoio.

Às diferentes categorias profissionais da enfermagem cabe uma parcela diferente do trabalho, com peculiaridades de desempenho e desigualdades 
sociais. Essa divisão do trabalho acarreta a fragmentação das ações e, sobretudo, uma marcante separação entre a concepção e a execução do processo de trabalho, expressa pelo fracionamento do denominado cuidado direto e indireto (Peduzzi, 2002; Peduzzi e Anselmi, 2002).

Os atos mais técnicos e socialmente mais qualificados (cuidado indireto) são realizados pelos enfermeiros, responsáveis pela chefia, coordenação e supervisão do trabalho dos auxiliares e técnicos de enfermagem, que por sua vez executam o trabalho menos qualificado, dedicando mais tempo aos enfermos (cuidado direto). As tarefas por eles realizadas são mais intensas, repetitivas e social e financeiramente menos valorizadas (Elias e Navarro, 2006).

Quanto aos enfermeiros, percebe-se a preocupação com os aspectos administrativos e organizacionais para que a assistência de enfermagem ocorra, ou seja, o cuidado indireto.

Recebo plantão, vou fazer a divisão das atividades, das tarefas dos funcionários e ver a demanda do dia (...) vejo o dimensionamento de funcionários (...) tem também a parte educativa, né, que muitas vezes a gente fala: “Hoje eu vou orientar os funcionários sobre tal assunto..." (E6).

Apesar da evolução das práticas científicas em administração, em muitas unidades hospitalares ainda são utilizados princípios da administração propostos por Taylor e Fayol, os quais enfatizam a divisão e a fragmentação do trabalho e a rigidez hierárquica. $\mathrm{O}$ que condiz com os achados deste estudo.

\section{História sobre saúde e adoecimento no e/ou pelo trabalho}

Verificamos, mais uma vez, a caracterização do trabalho como local de socialização, transparecendo o medo de ficar em casa, medo da solidão.

Quando eu tiro férias, eu tiro sempre vinte dias, sabe, mas aí vai chegando uma época eu já tô sentindo falta daqui, você entendeu? Não é tanta falta do dinheiro, é falta dos relacionamentos (...) porque em casa eu fico sozinha, né? (E5).

No trabalho você vê pessoas diferentes, problemas diferentes, você tenta assim resolver ou esclarecer, sabe, acolhe o paciente, acolhe o funcionário, é uma vida diferente, porque só ficar em casa, eu não me acerto com isso (E9).

O trabalho tem sido considerado ponto central, inclusive fornecendo uma identidade ao trabalhador que, de outra maneira, nem sempre consegue alguma forma de se mostrar existindo e relacionando-se (Gonzales e Beck, 2002). 
Ficar parado. Eu fico nervoso, sei lá... Ficar dentro de casa é uma morte pra mim (E4).

Eu não gosto de ficar em casa. Tem esse detalhe, se eu fico em casa, eu fico triste, sabe? (E11).

Sabemos que a ligação entre adoecimento e situação de trabalho não é simples, uma vez que tal processo é específico para cada indivíduo, envolvendo sua história de vida e de trabalho. Para estabelecer o nexo, torna-se fundamental a descrição detalhada da situação de trabalho quanto ao ambiente, à organização e à percepção da influência do trabalho no processo de adoecer (Glina et al., 2001). Assim, com base nas histórias de vida e trabalho dos narradores, tentamos desvelar como a organização e o processo de trabalho influenciam no processo saúde-doença dessas pessoas e como elas percebem essa influência.

Podemos constatar que os problemas de saúde apresentados pelos depoentes condizem com dados da literatura que trazem as doenças osteoarticulares como grande motivo de queixas pelos trabalhadores da enfermagem, assim como os problemas em relação à saúde mental. As lesões musculoesqueléticas na enfermagem estão relacionadas com esforços pesados e repetitivos (por exemplo: levantar/transferir pacientes) (Sofie, Belza e Young, 2003), assim como equipamentos e ambientes inadequados, altas demandas de trabalho e equipe inadequada (Yassi, Gilbert e Cvitkovich, 2005).

Na coluna, eu fiquei travadão, por causa de um paciente muito pesado que a gente tava cuidando (E7).

Eu entrei sem problema de coluna e tô, problema sério de coluna, e eu não tinha isso, de jeito nenhum. Agora fico com a coluna travada de vez em quando (...) desgaste, né, do dia a dia... (E10).

Eu tenho dor nas costas, tenho dor nesse braço aqui, que eu tenho uma lesão no nervo aqui... (E19).

Além do transporte e movimentação de pacientes e equipamentos, o comprometimento lento e gradativo da saúde desses trabalhadores pode ser provocado por longa permanência em pé durante o cuidado prestado, em associação com a má postura corporal e a inadequação do espaço físico e mobiliário. Dessa forma, maior atenção deve ser direcionada às posturas adotadas pelos trabalhadores na execução das atividades laborais e nas condições dos mobiliários, bem como se faz necessário disponibilizar instrumentos e equipamentos ergonomicamente planejados, visando-se à redução da incidência dos problemas osteomusculares (Murofuse e Marziale, 2005). 
Os transtornos mentais e comportamentais podem ser explicados tanto pelo estresse vivenciado na profissão (convívio com o sofrimento, com a dor, com a morte) quanto pelo excesso de trabalho, ou seja, tempo de descanso inadequado para recuperação do estresse fisiológico e mental provocado pela função - visto que é comum se manter dupla e até tripla jornada, seja em casa, seja num segundo ou terceiro emprego (Carvalho et al., 2010).

Eu tive depressão (...) fiquei dois anos em tratamento (E15).

Passei por uns pedaços muito difíceis (...) Já fui internada na psiquiatria, já saí, graças a Deus, ainda faço acompanhamento médico... (E13).

Há dois anos e meio eu 'entrei em parafuso', passei pela psiquiatria, fiquei quinze dias afastada (...) Eu andava nervosa, estressada, insegura, já achei que eu não sabia mais fazer o meu serviço (E11).

Quando indagados se relacionam a(s) doença(s) ao trabalho, alguns fazem essa associação.

Porque aqui a gente pega muito peso (...) Elevador que às vezes não funciona direito, essas macas horríveis, não sou só eu que tenho problema, muitos funcionários têm esse problema... (E10).

O estresse que a gente vivencia aqui... Eu era hipotensa e não hipertensa, mas a gente passa por muitas situações estressantes, falta de funcionários, falta de recurso material, depende da chefia, dos nossos gestores, a visão deles... (E6).

Outros têm dificuldade em fazer essa relação, atribuindo ao próprio envelhecimento e aos hábitos de vida a condição de saúde atual.

Acho que é devido ao tempo mesmo, a gente vai pegando uma idade, vai adquirindo... (E15).

Esses últimos anos eu fumei muito, fumei quarenta anos (...) pra mim era muita gordura. Com o trabalho não tem relação nenhuma, não foi nada disso, não (...) Eu tinha uma vida desregrada também, né... (E4).

Às vezes, existem grandes dificuldades por parte dos trabalhadores em relacionar os agravos à saúde que aconteceram em longo prazo com a exposição às cargas de trabalho em determinado momento da vida laboral. 


\section{História do envelhecimento no e/ou pelo trabalho}

Consideramos a velhice como uma fase do processo de envelhecimento, mas para os narradores não existe essa diferença. O significado relacionado às pessoas idosas ainda é, neste estudo, majoritariamente negativo.

Agora, eu acho que envelhecer é isso, perder tudo que é de bom da vida... (E14).

Ser velho pra mim é você não ter mais energia (...) a vontade de não querer mais viver, isso que é ser velho, ele perde a sua energia vital (E16).

Ficar doentinho, cheio de dor, hipertenso, diabético... (E17).

Os depoentes percebem alguns aspectos do envelhecimento, principalmente aqueles relacionados às questões físicas.

(...) é que primeiro eu corria o dia inteiro e não sentia dor nas pernas, agora eu começo a sentir (E4).

Algumas vezes eles percebem o próprio envelhecimento ao reconhecer o envelhecimento do outro.

Meus colegas tudo de cabelo branco, nossa, o meu também tá... Será que eu tô tão velha assim? (E13).

Outras vezes denominam essa fase da vida como um estado de espírito.

Eu sou velha de rosto, mas de alma, não. Eu sou velha de rosto, de corpo, não me sinto velha, não (E15).

Depreendemos das falas dos depoentes que o envelhecimento é silencioso, não é percebido na sua plenitude. Na maior parte das vezes apenas é identificado quando o indivíduo tem comprometida a sua capacidade funcional, quando compara a sua imagem atual com fotos de tempos passados ou com o envelhecimento de outras pessoas - suas contemporâneas (Souza, Matias e Brêtas, 2010).

As pessoas não aceitam o envelhecimento em razão também da falta de uma 'razão de ser' da velhice, por não encontrarem um papel para si mesmas na sociedade. Este é o primeiro impacto do envelhecimento para o indivíduo: a perda de seus papéis sociais e o vazio experimentado por não encontrar novas funções (Paschoal, 2000). 
Em nossa sociedade, ser velho significa, na maioria das vezes, estar excluído de vários lugares sociais. Um desses lugares, densamente valorizado, é aquele relativo ao sistema produtivo, o mundo do trabalho. Essa exclusão do mundo produtivo, extremamente valorizado na nossa cultura, espalha-se e cria barreiras impeditivas de participação do velho nas outras tantas e diversas dimensões da vida social (Mercadante, 2000). Tal discussão nos remete à ideia de que atrelado à aposentadoria temos o risco do isolamento; então, antes da morte física, o idoso vive a morte social (Elias, 2001).

No entanto, os narradores estão trabalhando, ou seja, se mantêm ativos no mercado do trabalho. Logo, eles não se consideram velhos. Alguns depoentes se sentem mais valorizados, em razão da experiência adquirida.

Hoje eu sou mais valorizado, hoje eu percebo não só aqui pela minha chefia, mas por outras colegas aqui (E12).

Eu tenho uma experiência muito maior, que nem uma pessoa que tá entrando agora não tem a experiência que eu tenho, e pra mim isso é importante... (E19).

Outros se sentem menos valorizados, acreditam que a experiência não é levada em conta, e algumas vezes são até marginalizados, considerados mais resistentes a mudanças.

Em termos de valorização, nenhuma, muito pelo contrário: a gente, às vezes, até mais marginalizado, porque já tem essa visão de quem tá ali mais velho é mais resistente (E1).

Tal sentimento também é gerado pela falta de um plano de carreira.

(...) muito pelo contrário. Apesar da experiência, tudo, a gente não tem mais valor que uma que entra nova. Eu percebo (...) por parte da instituição, de incentivo assim, da gente melhorar. Não tem plano de carreira, não tem nada assim que pudesse (...) Assim, pra gente sempre vale o conhecimento, mas pra crescer, não (E18).

A impossibilidade de ascensão na carreira contribui para a insatisfação e desmotivação do trabalhador. Mais uma vez fica evidente a importância do trabalho na vida desses trabalhadores. Percebemos que existe uma preocupação com a questão financeira, mas não é o fator determinante para mantê-los no mercado de trabalho. Existe o medo da solidão, o medo de ficar em casa, de se sentir inútil.

Pra mim é ótimo, viu, eu aconselho a todos, que envelhecendo assim aí ele não se julga inútil, certo? (E2). 
Não sei fazer outra coisa. Minha vida foi sempre dentro do hospital ou farmácia, não sei fazer outra coisa (E4).

Se está bem, por que não trabalhar? Se sente bem... Eu me sinto bem, acho que sinto que é bom pra mim, sei lá, acho que a gente tem algum valor... (E10).

Eu prefiro continuar trabalhando, porque se eu parar eu acho que vou ficar doente. Se eu parar de trabalhar, vou ter que fazer outra coisa que eu acho que, sei lá, minha vida é isso aqui, eu descobri que minha vida é isso aqui (E13).

Para os narradores, quem envelhece são os velhos. O significado relacionado às pessoas idosas ainda é majoritariamente negativo. Eles percebem alguns aspectos do próprio envelhecimento, principalmente aqueles relacionados às questões físicas. Algumas vezes percebem o envelhecimento ao reconhecer o envelhecimento do outro; outras vezes, denominam essa fase da vida como um estado de espírito.

Além da imagem negativa e pejorativa associada ao velho/velhice nas sociedades capitalistas, as pessoas não aceitam o envelhecimento com tranquilidade em razão da perda de seus papéis sociais. Assim, a importância do trabalho na vida dessas pessoas e a ideia de inutilidade causada pela perda do papel profissional justificam, em parte, por que muitos continuam no mercado de trabalho mesmo após a aposentadoria.

\section{Considerações finais}

Este estudo tratou do impacto que os processos e a organização do trabalho têm na vida e, consequentemente, no envelhecimento dos trabalhadores e trabalhadoras da área de enfermagem, compreendendo os significados que eles atribuem ao próprio processo de envelhecimento no mercado de trabalho e as implicações na saúde individual e familiar.

Em razão da pouca valorização social e da baixa remuneração, é comum os profissionais da enfermagem manterem dois ou mais empregos. Quando, então, indagados sobre a rotina de vida, notamos que ela se mistura com a rotina de trabalho. Quanto às mulheres, ainda são as principais responsáveis pelo trabalho doméstico e cuidado dos filhos e netos. Assim, podemos afirmar que o trabalho não só faz parte como ocupa lugar de destaque nas vidas desses trabalhadores. Além de garantir sua subsistência, é por meio dele que participam da sociedade e criam laços afetivos. Apesar da condição indispensável atribuída ao trabalho, também encontramos neste estudo relatos de insatisfação, o que está relacionado, principalmente, com a maneira como ele está organizado. 
Além das repercussões referentes às transformações do mundo do trabalho, no contexto mundial, o trabalho da enfermagem hospitalar sofre influências decorrentes da exposição às cargas de trabalho. Neste estudo, identificamos que as cargas de materialidade externa (cargas físicas, químicas, biológicas e mecânicas) geram impactos à saúde da equipe de enfermagem. Mas a exposição às cargas de materialidade interna (cargas fisiológicas e psíquicas) foram as mais referidas pelos trabalhadores. Quanto às cargas fisiológicas, as maiores queixas referiram-se aos esforços físicos e posições incômodas para a prestação do cuidado e sobrecarga de atividades (horas extraordinárias, dupla ou tripla jornada de trabalho). Quanto às cargas psíquicas, foram relatadas a forma de organização e divisão do trabalho e as relações de poder estabelecidas como geradoras de estresse.

As condições de trabalho a que estão submetidos os sujeitos do estudo não são diferentes daquelas enfrentadas pelos profissionais de enfermagem amplamente discutidas na literatura: falta de pessoal, falta de material, ambientes e equipamentos insuficientes ou inadequados, chefia controladora, falta de autonomia na tomada de decisões, falta de valorização do trabalho e de reconhecimento social. Sabemos que essa realidade não afeta apenas o trabalhador, mas também a pessoa que recebe os cuidados.

Os achados indicam relações sociais/afetivas no trabalho como satisfatórias e relações hierárquicas/profissionais como conflituosas. Isso nos leva a refletir sobre disciplina e hierarquia na enfermagem, sendo que em relação aos trabalhadores a disciplina paralisa a movimentação, aplaca a energia de lutar pelos seus direitos e dociliza os corpos para extrair a máxima potência deles.

Os narradores demonstram em suas falas a necessidade de participar mais ativamente das decisões, tanto para a própria satisfação e consequente maior qualidade de vida no trabalho quanto para a melhoria do serviço prestado. No entanto, o que se nota é que a instituição em questão é regida, majoritariamente, por uma administração vertical e hierarquizada, existindo distância entre o trabalhador e a administração e uma ausência de valorização do trabalhador como sujeito que age e interage para o processo de trabalho.

No que se refere à participação dos trabalhadores da enfermagem no processo de decisão, fica clara a necessidade de criação de espaços institucionais que proporcionem maior interação entre eles, onde possam ser ouvidos e participar de decisões que dizem respeito também a eles. Chama-nos a atenção a falta de participação coletiva e de visão grupal, na forma de atuação nos sindicatos e em outras entidades de classe, assim como a ausência de esforços conjuntos para mudar a realidade. Parece existir um processo de alienação da realidade vivenciada.

Também em relação à hierarquia e à disciplina, vale fazermos uma reflexão sobre o aumento do assédio moral nas instituições, principalmente 
nas mais hierárquicas, onde o medo é utilizado como forma de coagir as pessoas. Pudemos apreender das falas dos depoentes a existência desse tipo de relação, em que pessoas em cargos superiores exercem o seu poder utilizando-se da prepotência e arrogância para tratar os demais membros da equipe.

O que observamos neste estudo é que conforme os trabalhadores vão envelhecendo ou adoecendo eles acabam transferidos para setores de menor complexidade ou exercendo atividades mais leves. Essa também é uma realidade dos atendentes de enfermagem, por não poderem mais prestar cuidados diretos aos pacientes.

O que trazemos à discussão é que ao serem colocados em uma unidade ou função mais leve, os profissionais da enfermagem já teriam sua saúde comprometida, em razão de anos e anos em trabalhos pesados, desgastantes e estressantes. Além disso, ao mesmo tempo que poupa o trabalhador do desgaste físico - na maioria das vezes já estabelecido -, a mudança de local de trabalho ou função pode causar a sensação de desvalorização do trabalho.

Acreditamos que é preciso olhar para o modo como o trabalho de enfermagem tem contribuído para o adoecimento desses profissionais, a ponto de eles não conseguirem permanecer em unidades de maior complexidade até o fim de sua carreira.

Outro ponto a ser considerado é a crescente longevidade das populações, o que vem produzindo mudanças profundas no perfil etário dos trabalhadores e redelineamento das relações de trabalho em praticamente todo o mundo. Pelas narrativas dos depoentes, constatamos que o trabalho continua sendo uma atividade importante conforme eles envelhecem, e que o ambiente e a forma como o trabalho está organizado influenciam um envelhecimento saudável ou não. Assim, o desafio da enfermagem não está relacionado apenas ao seu próprio envelhecimento saudável no mercado de trabalho, mas também ao preparo em se trabalhar com pessoas envelhecendo nesse ambiente.

É árdua a tarefa de formular proposições que impliquem real melhoria da condição dos trabalhadores. No tocante aos da saúde, a preocupação deve ser focada nas relações e condições de trabalho em si, pois impactam tanto no viver, no adoecer, no envelhecer e no morrer dos trabalhadores como na qualidade do serviço prestado. 


\section{Colaboradores}

Marcia Renata Rodrigues realizou a proposta e participou de todas as etapas do estudo, trabalhou na concepção e redação do artigo. Ana Cristina Passarella Brêtas orientou a pesquisa, contribuiu com a redação do artigo. As autoras declaram que não há conflito de interesses.

Resumen Este estudio cualitativo buscó comprender los significados que los trabajadores de enfermería atribuyen al proceso de envejecimiento en el mercado laboral, identificando las implicaciones para la salud individual y familiar. Se utilizó el método de la historia oral temática, con veinte trabajadores de la enfermería de un hospital público en la ciudad de Marília, São Paulo, Brasil. En el análisis se revelaron tres categorías: historia del trabajo en la vida, historia sobre la salud y la enfermedad en y/o por el trabajo, historia del envejecimiento y/o por el trabajo. Inferimos que el trabajo ocupa un lugar de destaque, además de garantizar la subsistencia, propicia la participación en la sociedad. Encontramos relatos de insatisfacción con el trabajo, relacionada principalmente con la forma en que se organiza. Llegamos a la conclusión de que el trabajo sigue siendo una actividad importante durante toda la vida, y el ambiente y la forma de organizarlo influyen en el proceso de envejecimiento. El gran reto para la enfermería es formular proposiciones que impliquen una mejora real de las condiciones de sus trabajadores.

Palabras clave envejecimiento; trabajo; salud; enfermería; recursos humanos de enfermería en el hospital.

\section{Notas}

1 Faculdade de Medicina de Marília, Marília, São Paulo, Brasil.

Doutora em Enfermagem pela Universidade Federal de São Paulo.

$<$ marcia.renatarodrigues@gmail.com>

Correspondência: Rua dos Mandis, 142, CEP 17507-480, Marília, São Paulo, Brasil.

2 Universidade Federal de São Paulo, São Paulo, Escola Paulista de Enfermagem, SP, Brasil.

Doutora em Enfermagem pela Universidade Federal de São Paulo.

<acpbretas@ymail.com>

3 Este artigo relata parte da tese de doutorado $O$ envelhecimento no mercado de trabalho na perspectiva de trabalhadores e trabalhadoras da área de enfermagem (Rodrigues, 2012), defendida no Programa de Pós-Graduação em Enfermagem da Universidade Federal de São Paulo. 


\section{Referências}

BRASIL. Ministério da Saúde. Conselho Nacional de Saúde. Resolução n. 196/96, de 16 de outubro de 1996. Aprova as diretrizes $e$ normas regulamentadoras de pesquisas envolvendo seres humanos. Brasília, 1996. Disponível em: <http://conselho.saude.gov. br/resolucoes/reso_96.htm >. Acesso em: 3 ago. 2011.

BRASIL. Ministério da Saúde. Secretaria de Gestão de Investimentos em Saúde. Projeto de Profissionalização de Trabalhadores da Área de Enfermagem. Supervisão do Profae: documento de orientação. Brasília: Ministério da Saúde, 2001. (Série A: normas e manuais técnicos, n. 21). Disponível em: <http:// bvsms.saude.gov.br/bvs/publicacoes/ Orientacao_para_Supervisao.pdf $>$. Acesso em: 12 abr. 2011.

BRÊTAS, Ana C. P.; OLIVEIRA, Eleonora M. Envelhecimento, saúde e trabalho: um estudo com aposentados e aposentadas. Acta Paulista de Enfermagem, São Paulo, v. 13, n. 1, p. 66-79, jan./abr. 2000.

CARVALHO, Luciana S. F. C. et al. Motivos de afastamento por licença de saúde dos trabalhadores de enfermagem. Ciência, Cuidado e Saúde, Maringá, n. 9, v. 1, p. 60-66, jan./mar. 2010.

DEJOURS, Christophe. Por um novo conceito de saúde. Revista Brasileira de Saúde Ocupacional, São Paulo, v. 14, n. 54, p. 7-11, abr./jun. 1986.

DEJOURS, Christophe. A loucura do trabalho: estudo de psicopatologia do trabalho. 5. ed. São Paulo: Cortez, 1992.

DEJOURS, Christophe. A carga psíquica do trabalho. In: BETIOL, Maria I. S. (Coord.). Psicodinâmica do trabalho: contribuições da Escola Dejouriana à análise da relação prazer, sofrimento e trabalho. São Paulo: Atlas, 2007. p. 21-32.

ELIAS, Maria A.; NAVARRO, Vera L. A relação entre trabalho, a saúde e as condições de vida: negatividade e positividade no trabalho das profissionais de enfermagem de um hospital escola. Revista Latino-Americana de Enfermagem, Ribeirão Preto, v. 14, n. 4, p. 517-525, jul./ago. 2006.

ELIAS, Norbert. A solidão dos moribundos seguido de envelhecer e morrer. Rio de Janeiro: Jorge Zahar, 2001.

GLINA, Débora M. R. et al. Saúde mental e trabalho: uma reflexão sobre o nexo com o trabalho e o diagnóstico, com base na prática. Cadernos de Saúde Pública, Rio de Janeiro, v. 17, n. 3, p. 607-616, maio/jun. 2001.

GONÇALVES, Leonor; MAGALHÃES, Zídia R. Acompanhamento do trabalhador de enfermagem em reabilitação: a experiência de um hospital universitário. Texto \& Contexto Enfermagem, Florianópolis, v. 12, n. 4 , p. 519-527, out./dez. 2003.

GONZALES, Rosa M. B.; BECK, Carmem L. C. O sofrimento e o prazer no cotidiano dos trabalhadores da enfermagem. Texto \& Contexto Enfermagem, Florianópolis, v. 11, n. 1, p. 169-186, jan./abr. 2002

GUIMARÃES, Celma M. et al. Organização e relações de trabalho na área de enfermagem: análise do conhecimento produzido entre 1971 e 2002. Texto \& Contexto Enfermagem, Florianópolis, v. 12, n. 4, p. 479-485, out./dez. 2003.

HELOANI, Roberto. Assédio moral: um ensaio sobre a expropriação da dignidade no trabalho. Revista de Administração de Empresas, São Paulo, v. 3, n. 1, jan./jun. 2004. Disponível em: <www.scielo.br/scielo. php? script $=$ sci_arttext \& pid $=$ S 1676 56482004000100013>. Acesso em: 18 jan. 2012.

HELOANI, Roberto. Assédio moral: a dignidade violada. Aletheia, Canoas, n. 22, p. 101-107, jul./dez. 2005.

HELOANI, Roberto. Práticas organizacionais e sofrimento psíquico: o que a psicologia do 
trabalho tem a ver com isso? In: SEMINÁRIO NACIONAL DE SAÚDE MENTAL E TRABALHO, 1, 2008. São Paulo. Anais eletrônicos... São Paulo: Fundacentro, 2008. Mesa-redonda 2. Disponível em: <www. fundacentro.gov.br/Arquivos/sis/Evento Portal/AnexoPalestraEvento/Mesa \% 202\% 20-\%20Roberto\%20Heloani.pdf>. Acesso em: 20 jan. 2012.

MERCADANTE, Elisabeth. Aspectos antropológicos do envelhecimento. In: PAPALÉO NETTO, Matheus. Gerontologia: a velhice e o envelhecimento em visão globalizada. São Paulo: Atheneu, 2000. p. 73-76.

MUROFUSE, Neide T.; MARZIALE, Maria H. P. Doenças do sistema osteomuscular em trabalhadores de enfermagem. Revista Latino-Americana de Enfermagem, Ribeirão Preto, v. 13, n. 3, p. 364-373, maio/jun. 2005.

PASCHOAL, S. M. P. Epidemiologia do envelhecimento. In: PAPALÉO-NETTO, Matheus. Gerontologia: a velhice e o envelhecimento em visão globalizada. São Paulo: Atheneu, 2000. p. 26-43.

PEDUZZI, Marina. Laços, compromissos e contradições existentes nas relações de trabalho da enfermagem. In: CONGRESSO BRASILEIRO DE ENFERMAGEM, 53, 2001, Curitiba. Anais... Curitiba: ABEn-PR, 2002. p. 167-182.

PEDUZZI, Marina; ANSELMI, Maria L. O processo de trabalho de enfermagem: a cisão entre planejamento e execução do cuidado. Revista Brasileira de Enfermagem, Brasília, v. 55, n. 4, p. 392-398, jul./ago. 2002.

RODRIGUES, Marcia R. As relações entre as concepções dos idosos e dos auxiliares de enfermagem sobre o cuidado em ambiente hospitalar. Dissertação (Mestrado) - Universidade Federal de São Paulo, São Paulo, 2002.
RODRIGUES, Marcia R. O envelhecimento no mercado de trabalho na perspectiva de trabalhadores e trabalhadoras da área de enfermagem. Tese (Doutorado em Enfermagem) Universidade Federal de São Paulo, São Paulo, 2012.

SECCO, Iara A. O. et al. Cargas psíquicas de trabalho e desgaste dos trabalhadores de enfermagem de hospital de ensino do Paraná, Brasil. SMAD - Revista Eletrônica Saúde Mental, Álcool e Drogas, Ribeirão Preto, v. 6, n. 1, 2010. Disponível em: <www. revistas.usp.br/smad/article/view/38713/ 41564>. Acesso em: 5 maio 2011.

SOFIE, Jennifer; BELZA, Basia; YOUNG, Heather. Health and safety risk at a skilled nursing facility: nursing assistants' perceptions. Journal of Gerontological Nursing, Thorofare, v. 29, n. 2, p. 13-21, Feb. 2003.

SOUZA, Rosangela F.; MATIAS, Hernani A.; BRÊTAS, Ana C. P. Reflexões sobre envelhecimento e trabalho. Ciência \& Saúde Coletiva, Rio de Janeiro, v. 15, n. 6, p. 2.835-2.843, 2010.

THOMPSON, Paul. A voz do passado: história oral. 2. ed. Rio de Janeiro: Paz e Terra, 1998.

YASSI, Annalee; GILBERT, Mark; CVITKO$\mathrm{VICH}$, Yuri. Trends in injuries, illnesses, and policies in Canadian healthcare workplaces. Canadian Journal of Public Health, Ottawa, v. 96, n. 5, p. 333-339, Sept./Oct. 2005.

Recebido em 14/01/2013

Aprovado em 10/06/2014 